International Journal of Engineering, Science and Technology

Vol. 3, No. 3, 2011, pp. 101-110
INTERNATIONAL

JOURNAL OF

ENGINEERING,

SCIENCE AND

TECHNOLOGY

wWw.ijest-ng.com

(C) 2011 MultiCraft Limited. All rights reserved

\title{
Bidirectional DC-DC converter fed drive for electric vehicle system
}

\author{
Premananda Pany $^{1 *}$, R.K. Singh ${ }^{2}$, R.K. Tripathi ${ }^{2}$

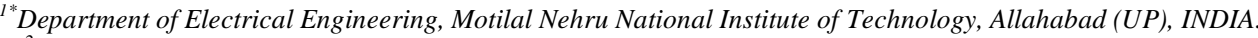 \\ ${ }^{2}$ Electrical Engineering Department, Motilal Nehru National Institute of Technology Allahabad (UP), INDIA \\ Corresponding author: e-mails: pnpany@gmail.com,Mob-09454950164
}

\begin{abstract}
Batteries are the primary energy-storage devices in ground vehicles. Now days battery fed electric drives are commonly being used for electric vehicles applications, due to various advantages, such as: nearly zero emission, guaranteed load leveling, good transient operation and energy recovery during braking operation. To fulfill these requirements converters with bidirectional power flow capabilities are required to connect the accumulator (battery) to the dc link of the motor drive system. Battery fed electric vehicles (BFEVs) is required to function in three different modes namely: acceleration mode, normal (steady-state) mode and braking (regenerative) mode. During acceleration and normal modes the power flow is from battery to motor where as during braking or regenerative mode the kinetic energy of the motor is converted into electrical energy and fed back to battery. The DC-DC converter is required to perform mainly two functions: first to match the battery voltage to the motor rated voltage and second to control the power flow under steady-state and transient conditions, so that the drive performance is as per the requirement. In the present work closed loop operation of bi-directional dc-dc converter feeding a dc motor and its energy recovery due to regenerative braking has been demonstrated. The characteristics of battery operated electric vehicle under different drive condition are also presented. The effectiveness of the system is verified through the simulations using Simulink/ MATLAB 7.6.0 (R2008a) package.
\end{abstract}

Keywords: Bi-directional dc-dc converter, separately excited dc motor, Battery.

\section{Introduction}

Recently bi-directional dc-dc converters are widely researched and developed for various applications such as battery chargerdischargers, electric vehicles and UPS systems. In case of the battery fed electric vehicles (BFEVs), electric energy flows between motor and battery side. For achieving zero emission, the vehicle can be powered only by batteries or other electrical energy sources. Batteries have widely been adopted in ground vehicles due to their characteristics in terms of high energy density, compact size, and reliability. This can be applied in Hybrid Electric Vehicle (HEVs) with a battery as an energy storage element to provide desired management of the power flows. In hybrid electric vehicle energy storage devices act as catalysts to provide energy boost. However the high initial cost of BFEVs as well as its short driving range has limited its use. Bidirectional dc-dc converters are the key components of the traction systems in Hybrid Electric Vehicles. The use of a Bi-directional dc-dc converter fed dc motor drive devoted to electric vehicles (EVs) application allows a suitable control of both motoring and regenerative braking operations, and it can contribute to a significant increase the drive system overall efficiency. Recently many Bidirectional dc-dc converter topologies have been reported with soft switching technique to increase the transfer efficiency (Zhang et al., 2007). Bi-directional converters using coupled inductor were introduced for soft-switching technique with hysteresis current controller (Zhang and Sen, 2003). For minimizing switching losses and to improve reliability, zero-voltage-switched (ZVS) technique and zero-current-switched (ZCS) technique were introduced for Bi-directional converter (Jain et al., 2002). A multiphase Bi-directional converter is suitable for high power application. To achieve high voltage rating or current rating more number of converters can be connected in series or parallel with low switching frequency (Yu and Lai, 2008). A unified current controller (Zhang et al, 2008) was introduced for Bi-directional dc-dc converter which employs complementary switching between upper and lower switches. 
This paper deals with the use of a Bi-directional dc-dc converter for a battery fed electric vehicle drive system. A closed loop speed control technique of the proposed battery fed electric vehicle is designed and implemented using PI controller. The overall drive system reduces the system complexity, cost and size of a purely electric based vehicular system.

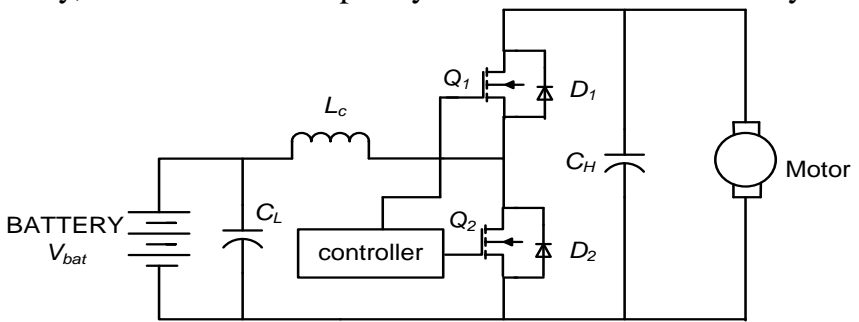

Figure1. Bidirectional dc-dc converter with battery and dc motor

Figure1 shows the proposed Bi-directional dc-dc converter fed DC motor drive. In this topology, boost converter operation is achieved by modulating $Q_{2}$ with the anti-parallel diode $D_{1}$ serving as the boost-mode diode. With the direction of power flow reversed, the topology functions as a buck converter through the modulation of $Q_{1}$, with the anti-parallel diode $D_{2}$ serving as the buck-mode diode. It should be noted that the two modes have opposite inductor current directions. A new control model is developed using PI controller to achieve both motoring and regenerative braking of the motor. A Lithium-ion battery model has been used in this model to verify the motor performance in both motoring and regenerative mode. This controller shows satisfactory result in different driving speed commands.

\section{Circuit Description}

2.1 Converter operation: The bidirectional dc-dc converter shown in Figure1 is operated in continuous conduction mode for forward motoring and regenerative braking of the dc motor. The MOSFETs $Q_{1}$ and $Q_{2}$ are switched in such a way that the converter operates in steady state with four sub intervals namely interval $1\left(t_{0}-t_{1}\right)$, interval $2\left(t_{1}-t_{2}\right)$, interval $3\left(t_{2}-t_{3}\right)$ and interval $4\left(t_{3}-\right.$ $t_{4}$ ). It should be noted that the low voltage battery side voltage is taken as $V_{l}$ and high voltage load side is taken as $V_{2}$. The gate drives of switches $Q_{1}$ and $Q_{2}$ are shown in Figure 3. The circuit operations in steady state for different intervals are elaborated below.

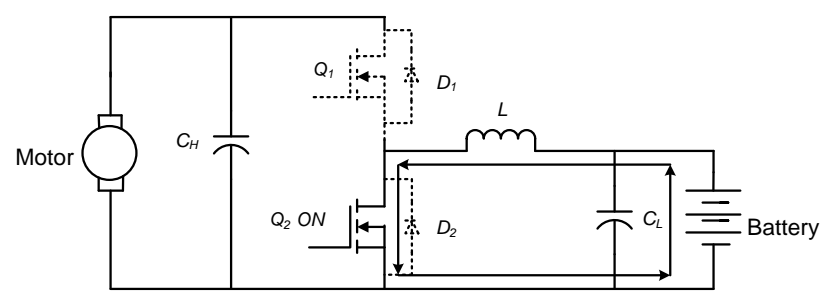

(a) Interval $\left(\mathrm{t}_{0}-\mathrm{t}_{1}\right)$.

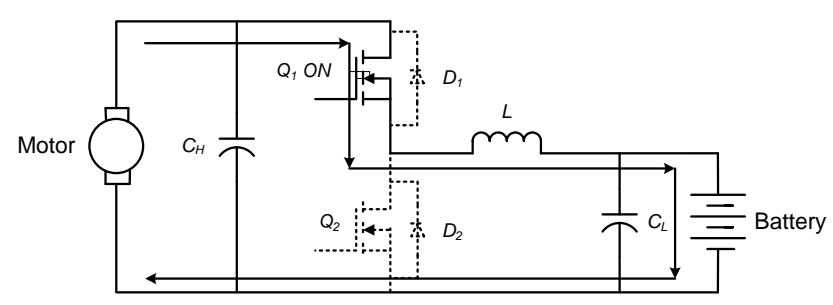

(c) Interval $\left(\mathrm{t}_{2}-\mathrm{t}_{3}\right)$.

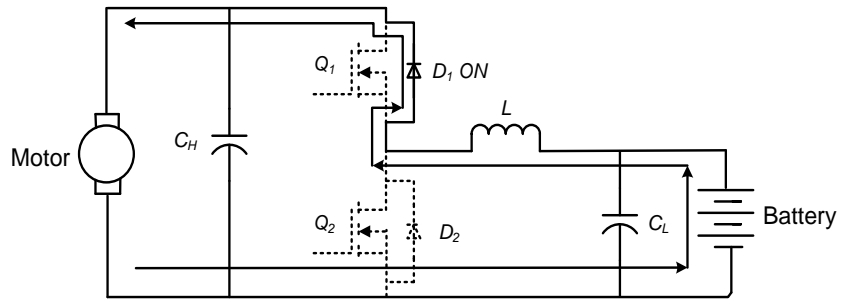

(b) Interval $\left(\mathrm{t}_{1}-\mathrm{t}_{2}\right)$.

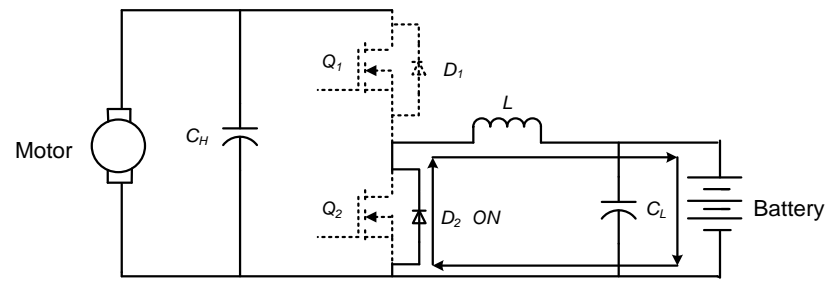

(d) Interval $\left(\mathrm{t}_{3}-\mathrm{t}_{4}\right)$.

Figure 2. Converter operating modes.

2.1.1 Interval 1 $\left(t_{0}-t_{1}\right)$ : At time $t_{0}$, the lower switch $Q_{2}$ is turned ON and the upper switch $Q_{1}$ is turned OFF with diode $D_{1}, D_{2}$ reverse biased as shown in Figure 2(a). During this time interval the converter operates in boost mode and the inductor is charged and current through the inductor increases.

$$
L_{C} \cdot \frac{d i_{L}}{d t}=V_{2}
$$




$$
\frac{d i_{a}}{d t}=\frac{V_{1}}{L_{a}}-\frac{E_{b}}{L_{a}}-\frac{r_{a}}{L_{a}} i_{a}
$$

2.1.2 Interval 2( $\left.t_{1}-t_{2}\right)$ : During this interval both switches $Q_{1}$ and $Q_{2}$ is turned OFF. The body diode $D_{1}$ of upper switch $Q_{1}$ starts conducting as shown in Figure 2(b). The converter output voltage is applied across the motor. As this converter operates in boost mode is capable of increasing the battery voltage to run the motor in forward direction.

$$
\begin{aligned}
& \frac{d V_{1}}{d t}=\frac{i_{a}}{c_{h}} \\
& \frac{d V_{2}}{d t}=\frac{V_{b}}{R_{b} \cdot C_{l}}-\frac{V_{2}}{R_{b} \cdot C_{l}}-\frac{i_{L}}{C_{l}}
\end{aligned}
$$

2.1.3 Interval 3(t $\left.t_{2}-t_{3}\right)$ : At time $t_{3}$, the upper switch $Q_{1}$ is turned ON and the lower switch $Q_{2}$ is turned OFF with diode $D_{1}, D_{2}$ reverse biased as shown in Figure 2(c). During this time interval the converter operates in buck mode.

$$
\begin{aligned}
& \frac{d i_{L}}{d t}=\frac{-V_{1}}{L_{C}}+\frac{V_{2}}{L_{C}} \\
& \frac{d V_{2}}{d t}=\frac{V_{b}}{R_{b} \cdot C_{l}}-\frac{V_{2}}{R_{b} \cdot C_{l}}-\frac{i_{L}}{C_{l}}
\end{aligned}
$$

2.1.4 Interval $4\left(t_{3}-t_{4}\right)$ : During this interval both switches $Q_{1}$ and $Q_{2}$ is turned OFF. The body diode $D_{2}$ of lower switch $Q_{2}$ starts conducting as shown in Figure 2(d).

$$
\begin{aligned}
\frac{d V_{1}}{d t} & =\frac{i_{L}}{C_{h}}-\frac{i_{a}}{C_{h}} \\
\frac{d i_{a}}{d t} & =\frac{V_{1}}{L_{a}}-\frac{E_{b}}{L_{a}}-\frac{r_{a}}{L_{a}} i_{a}
\end{aligned}
$$

The state space average model is shown in (9) and (10).

$$
\begin{gathered}
0=A \cdot\left[\begin{array}{c}
i_{L} \\
i_{a} \\
V_{1} \\
V_{2}
\end{array}\right]+B \cdot\left[\begin{array}{c}
E_{b} \\
V_{b}
\end{array}\right] \\
A=\left[\begin{array}{cccc}
0 & 0 & -\frac{(1-D)}{L_{C}} & \frac{1}{L_{C}} \\
\frac{(1-D)}{C_{h}} & \frac{-1}{C_{h}} & 0 & 0 \\
\frac{-1}{C_{l}} & 0 & 0 & -\frac{1}{L_{a}}
\end{array}\right] \quad B=\left[\begin{array}{cc}
\frac{1}{L_{b}} & 0 \\
0 & 0 \\
0 & \frac{1}{L_{a}}
\end{array}\right]
\end{gathered}
$$


Figure 3 shows the gate pulses of the upper and lower switches of the Bi-directional converter and is switched alternatively without any dead time in between. The control signals are obtained by comparing the modulating signal $V_{\text {triangular }}$ with the carrier signal $V_{\text {control. }}$

2.2 Converter design: The bi-directional converter is designed based on the input supply voltage and output voltage requirement to drive the electric vehicle at desired speed. The converter power topology is based on a half bridge circuit to control the dc motor. At a given input battery voltage and reference speed command the inductor current has a nearly constant peak to peak swing. The inductor is designed with a specified current ripple of $15 \mathrm{~A}$ and 20 $\mathrm{KHz}$ switching frequency.

Equations (11)-(13) are used to design the converter.

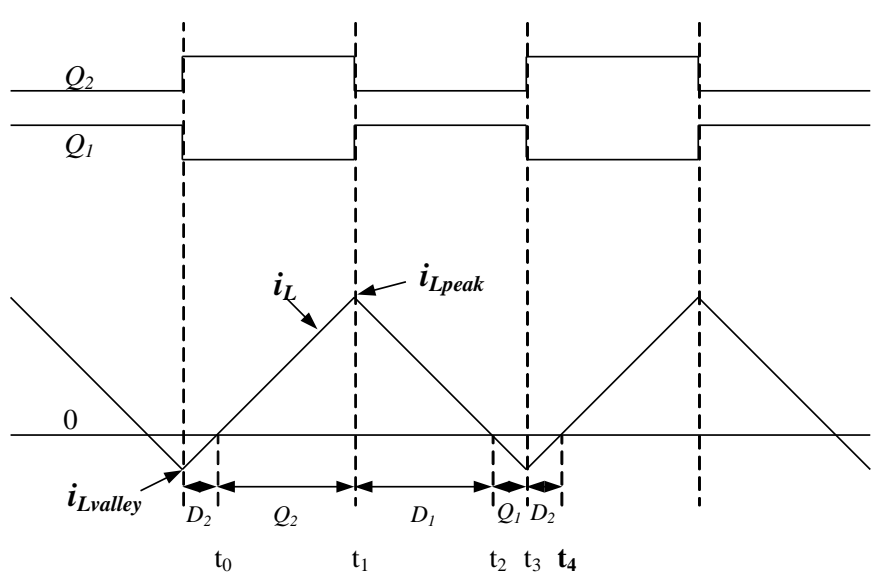

Figure 3. Complementary Gate Pulses

$$
\begin{aligned}
& \Delta I=\frac{1}{2} \cdot \frac{V_{2}-V_{1}}{L_{C}} \cdot \frac{V_{1}}{V_{2}} \cdot T_{S} \\
& I_{a}=\frac{P}{V_{2}} \\
& I_{r m s}=\sqrt{I_{\text {Load }}^{2}+\frac{\Delta I^{2}}{3}}
\end{aligned}
$$

2.3 DC motor modeling: The modeling of the DC motor has been carried out with torque and rotor angle consideration. The steady state motor torque $\mathrm{T}$ is related to armature current $\mathrm{I}$ and a torque constant $\mathrm{K}$.

$$
T_{m}=K I_{a}
$$

The back emf $E_{b}$, is related to angular velocity by

$$
\begin{aligned}
& E_{b}=K \omega_{m}=K \frac{d \theta}{d t} \\
& j \frac{d^{2} \theta}{d t^{2}}+b \frac{d \theta}{d t}=K I_{a} \\
& L \frac{d I_{a}}{d t}+R I_{a}=V-K \frac{d \theta}{d t}
\end{aligned}
$$

Transfer function using Laplace transformation, equations (16) and (17) can be written as

$$
\begin{gathered}
J s^{2} \theta(s)+b s(\theta)=k I_{a}(s) \\
L s I(s)+R I(s)=V(s)-K s \theta(s)
\end{gathered}
$$

where, $s$ denotes the Laplace operator.

From equation (19), the current can be expressed as 


$$
\begin{aligned}
& I(s)=\frac{V(s)-K \theta(s)}{R+L s} \\
& J^{2} \theta=b s \theta(s)=\frac{K(V(s)-K s \theta(s)}{R+L s}
\end{aligned}
$$

From equation (21), the transfer function from the input voltage $V(s)$ to the output angle $\theta$ can be written as

$$
G_{a}(s)=\frac{\theta(s)}{V(s)}=\frac{K}{\left\{s\left[(R+L s)(J s+b)+K^{2}\right]\right\}}
$$

The transfer function from the input voltage $V(s)$ to the angular velocity $\omega(\mathrm{s})$ is,

$$
G_{v}(s)=\frac{\omega(s)}{V(s)}=\frac{K}{\left[(R+L s)(J s+b)+K^{2}\right]}
$$

\section{Control Strategy}

The control circuit of the bidirectional converter is shown in Figure 4.To control the speed of the dc drive; one possible control option is to control the output voltage of the bidirectional converter. To control the output voltage of the bidirectional converter for driving the vehicle at desired speed and to provide fast response without oscillations to rapid speed changes a PI controller is used and it shows satisfactory result. In this control technique the motor speed $\omega_{m}$ is sensed and compared with a reference speed $\omega_{\text {ref }}$. The error signal is processed through the PI controller. The signal thus obtained is compared with a high frequency saw tooth signal equal to switching frequency to generate pulse width modulated (PWM) control signals.

High frequency

saw tooth signal

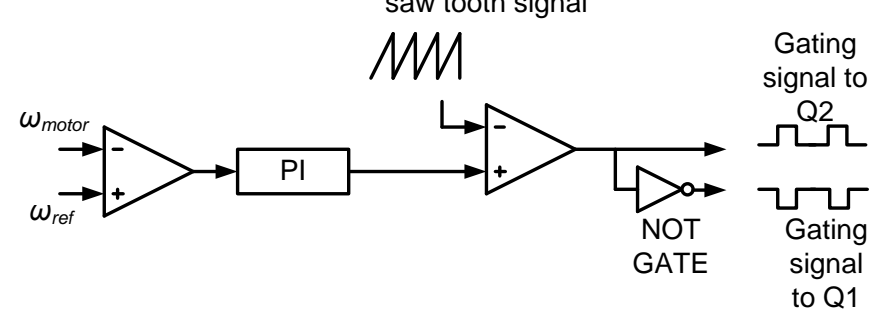

Figure 4. Control of the bidirectional dc-dc converter.

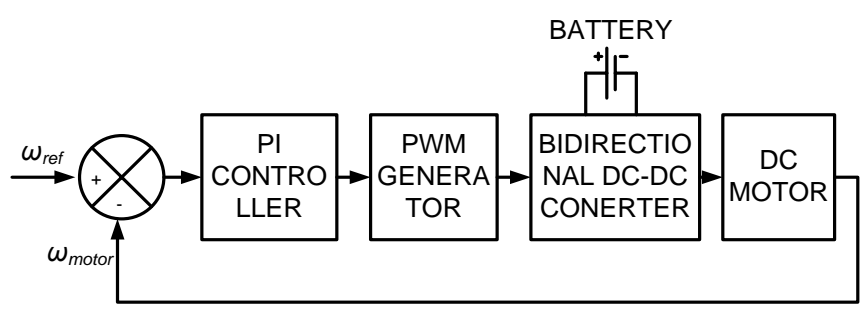

Figure 5. Closed loop operation of the drive.

The block diagram of feedback speed control system for DC motor drive is shown in Figure 5; the control objective is to make the motor speed follow the reference input speed change by designing an appropriate controller. The proportional-integral(PI) controller is used to reduce or eliminate the steady state error between the measured motor speed $\left(\omega_{\text {motor }}\right)$ and the reference speed $\left(\omega_{r e f}\right)$ to be tracked. The transfer function of PI controller is given by

$$
G_{c}(s)=K_{p}+\frac{K_{i}}{s}
$$

Where, $K_{P}$ and $K_{i}$ are the proportional and integral gains. The value of $K_{P}$ and $K_{i}$ are obtained by using Zeigler Nichols tuning method. Simulink model of the overall system is shown in figure 5.

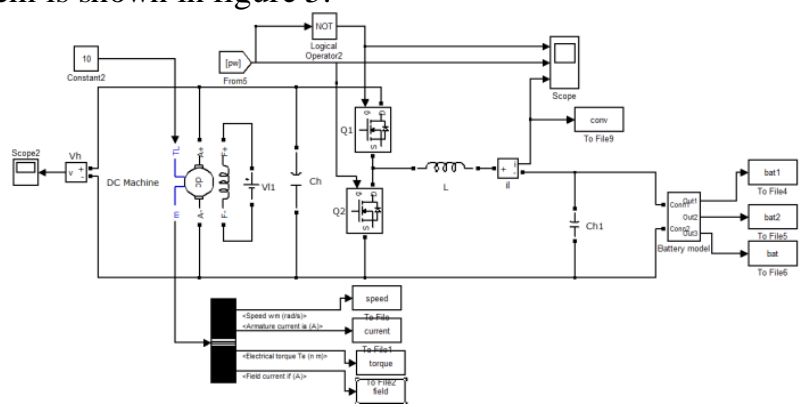

Figure 5. Simulink Model of the Drive system. 


\section{Battery Requirement for Automotive Application.}

Mainly Nickel-Metal hydride (NiMH) and Lithium-ion batteries are used in vehicular application due to their characteristics in terms of high energy density, compact size and reliability. The battery is being recharged by the regenerative capabilities of the electric motors which are providing resistance during braking helping to slow down the vehicle.

The lithium-ion battery has been proven to have excellent performance in portable electronics and medical devices .The lithiumion battery has high energy density, has good high temperature performance, and is recyclable. The promising aspects of the Li-ion batteries include low memory effect, high specific power of $300 \mathrm{~W} / \mathrm{kg}$, high specific energy of $100 \mathrm{Wh} / \mathrm{kg}$, and long battery life of 1000 cycles. These excellent characteristics give the lithium-ion battery a high possibility of replacing NiMH as next-generation batteries for vehicles. Equation (25) is used to estimate the state of charge (SOC) of the battery.

$$
V_{S O C}(t)=V_{S O C}(0)-\frac{1}{C_{C A P}} \int_{0}^{\tau} i(t) d \tau .
$$

\section{Simulation Results}

Performance of the dc motor drive with the above battery model and bidirectional converter is simulated under different speed command. The simulations are carried out using MATLAB/SIMULINK. The inductor parasitic resistance and MOSFET turn-on resistance are not considered in this case. For the test condition of the proposed drive topology the following values of the different components of the converter are considered. A separately excited DC motor model is used as load to the bidirectional dc-dc converter. The motor rated at $5 \mathrm{hp}, 240 \mathrm{~V}$, and $1750 \mathrm{rpm}$.

Principal parameters of the bidirectional converter are: $L=1600 \mu \mathrm{H}, C_{H}=470 \mu \mathrm{F}, C_{L}=470 \mu \mathrm{F}, f_{S W}=20 \mathrm{kHz}$ Battery voltage $=48 \mathrm{~V}$. Battery capacity $=16 \mathrm{Ah}, \mathrm{SOC}=88 \%$.

A total of two cases of the drive system are studied:1) steady state operation : the reference motor speed is $120 \mathrm{rad} / \mathrm{sec}$ with a constant torque demand of $10 \mathrm{Nm}, 2$ ) transient state operation: case (I) when the speed changes from $60 \mathrm{rad} / \mathrm{sec}$ to $120 \mathrm{rad} / \mathrm{sec}$ with a constant torque demand of $10 \mathrm{Nm}$ at time $\mathrm{t}=5 \mathrm{secs}$ and case (II) regenerative braking mode: the speed changes from $120 \mathrm{rad} / \mathrm{sec}$ to $0 \mathrm{rad} / \mathrm{sec}$. Torque changes from $+10 \mathrm{Nm}$ to $-10 \mathrm{Nm}$ at a step time of $5 \mathrm{secs}$. The simulation is carried out for (a) motor speed, (b) torque, (c) motor current, (d) battery state of charge (SOC), (e) battery voltage, (f) battery current, (g) battery power and motor power and (h) battery energy and motor energy characteristic during regenerative braking mode.

Case I. Steady State Results.

Figure 6(a) shows the simulation result of the drive system at a reference speed of $120 \mathrm{rad} / \mathrm{sec}$ for a total simulation time of 10 sec. Motor speed reaches at its steady state speed of $120 \mathrm{rad} / \mathrm{sec}$ at time less than $0.5 \mathrm{sec}$. Figure 6(b) (c) shows the motor torque and current of the drive respectively. The battery SOC was initially set at 88\%, Figure 6(d) shows the SOC of the battery, when the drive was running for $10 \mathrm{sec}$ at a speed of $120 \mathrm{rad} / \mathrm{sec}$. Figure 6(e) and (f) show the battery voltage and current under this condition. Figure $6(\mathrm{~g})$ shows the comparison between the battery power and motor power.

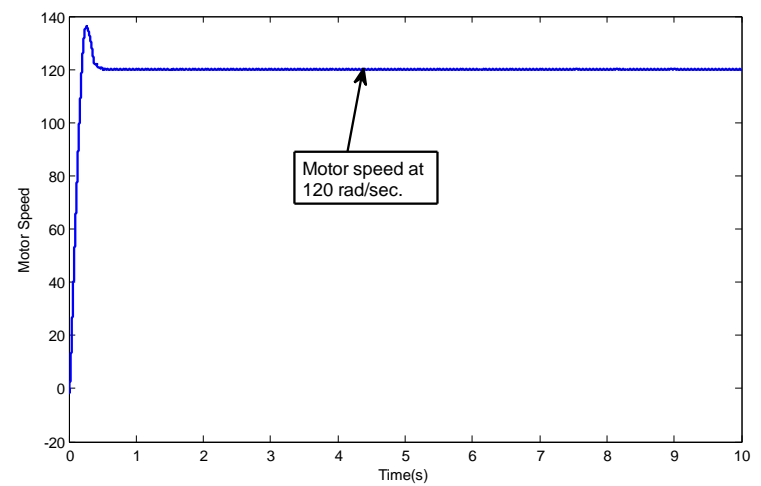

Figure 6(a). Motor speed

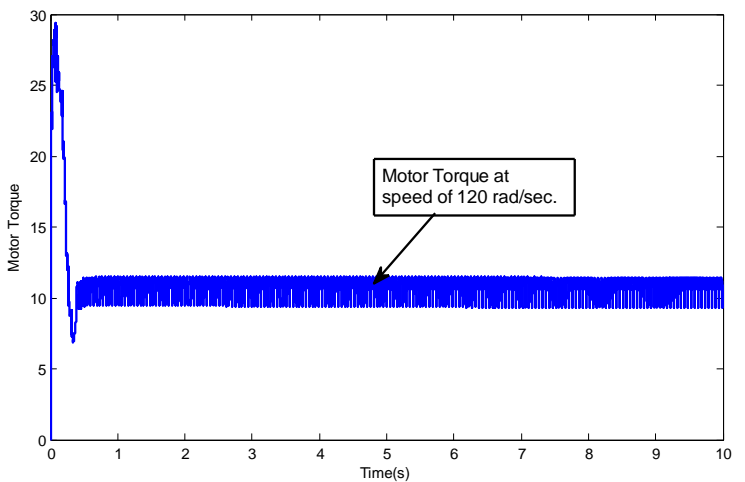

Figure 6(b). Motor Torque 


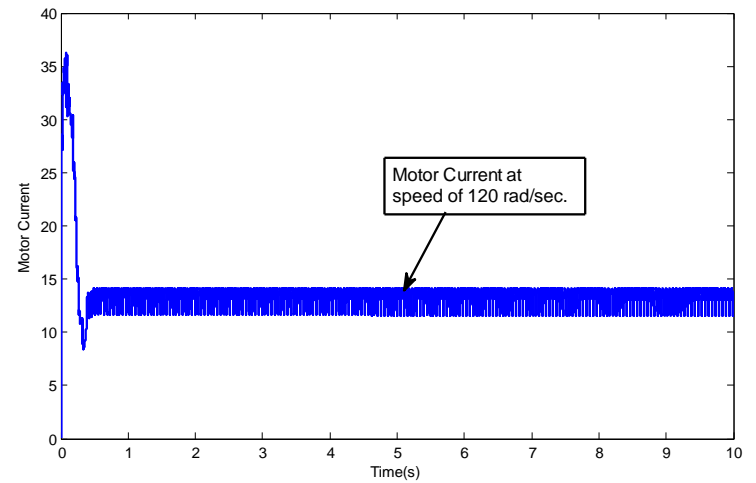

Figure 6(c). Motor current

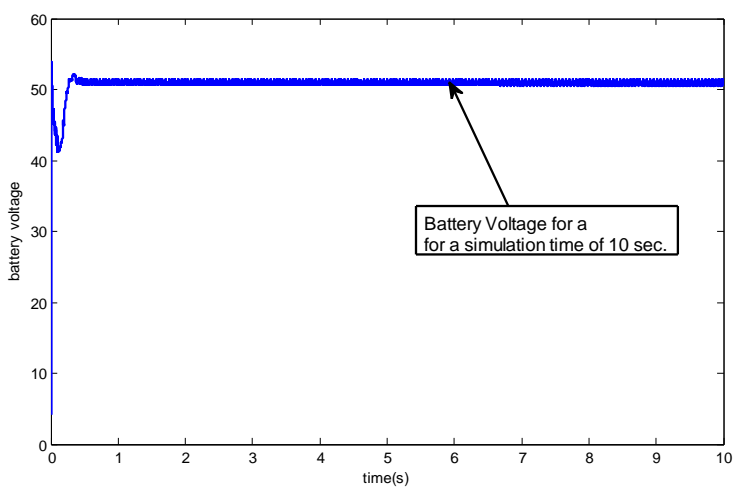

Figure 6(e). Battery voltage.

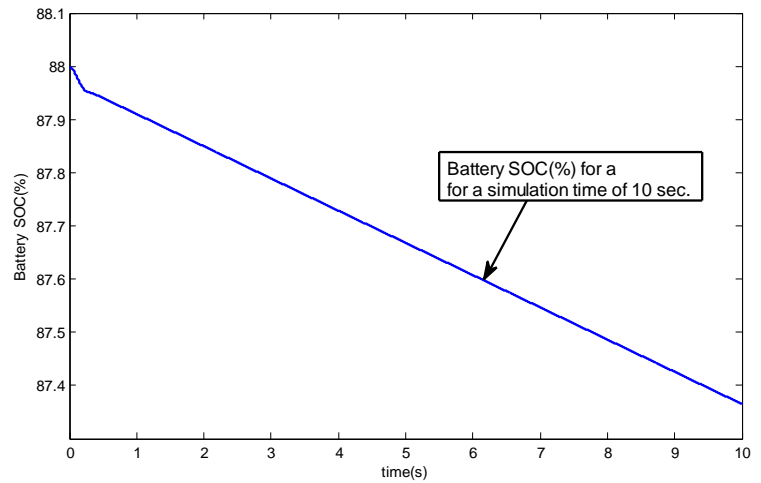

Figure 6(d). Battery State of charge

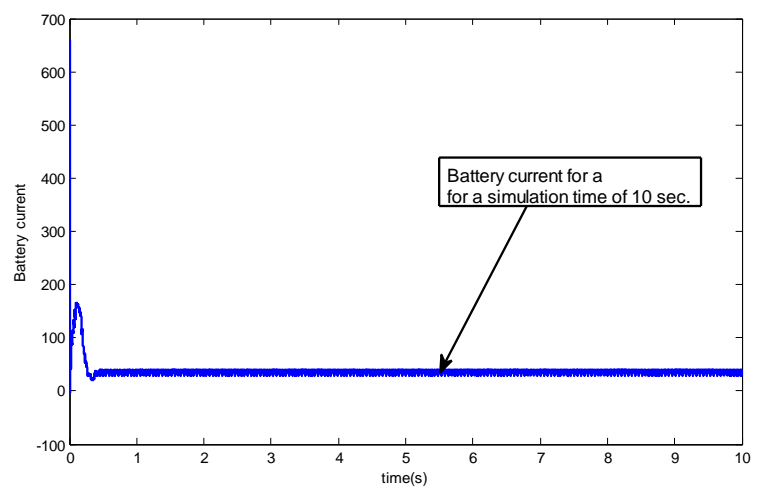

Figure 6(f). Battery current.

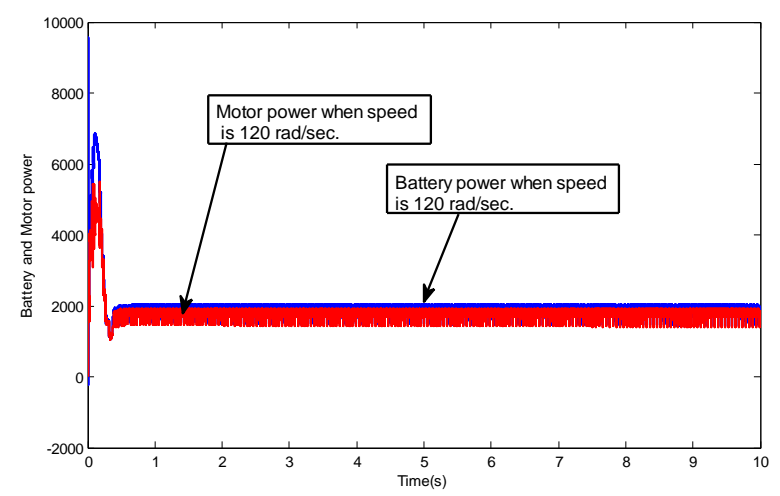

Figure 6(g). Motor and battery power.

Figure 6. Simulation result under steady state condition (motoring mode), speed reference $120 \mathrm{rad} / \mathrm{sec}$, simulation time of $10 \mathrm{sec}$, at constant torque of $10 \mathrm{Nm}$.

Case II. Transient State Results.

During transient, simulations are performed when the motor speed is changed from $60 \mathrm{rad} / \mathrm{sec}$ to $120 \mathrm{rad} / \mathrm{sec}$. Figure 7 (a) shows the speed curve under this condition for time of $5 \mathrm{sec}$. Figure 7(b) shows that the momentarily increase in torque when there is a sudden change in speed requirement. Figure $7(\mathrm{c})$ indicates the current which is same as the torque characteristic. When the speed increases, the motor draws more power from the source as shown in figure 7(d), the battery SOC. Figure 7(e) (f) shows the battery voltage and current under this condition. Figure $7(\mathrm{~g})$ indicates the power management curve of motor and battery under the same operating condition. Figure $7(\mathrm{~h})$ shows the battery and motor energy during the transient operation. These results show the satisfactory performance of drive under the step-up transients.

Simulations are also performed for the braking operation when the speed is changed from $120 \mathrm{rad} / \mathrm{sec}$ to $100 \mathrm{rad} / \mathrm{sec}$ while the motor torque and current has reverse characteristic as shown in Figure 8(a), (b) and Figure 8(c) respectively. Figure 8(d) shows the battery SOC during regenerative braking mode. Figure 8(e) and (f) shows the battery voltage and current respectively. Figure 8(g) shows the characteristics of motor power and battery power under the same drive condition. Figure 8(h) shows the battery energy characteristic in regenerative braking mode. The energy recovered by the battery in this mode is 3000J. The observation on steady 
state and transient state are shown in Table I. These results show the satisfactory performance of drive under the step-down transients.

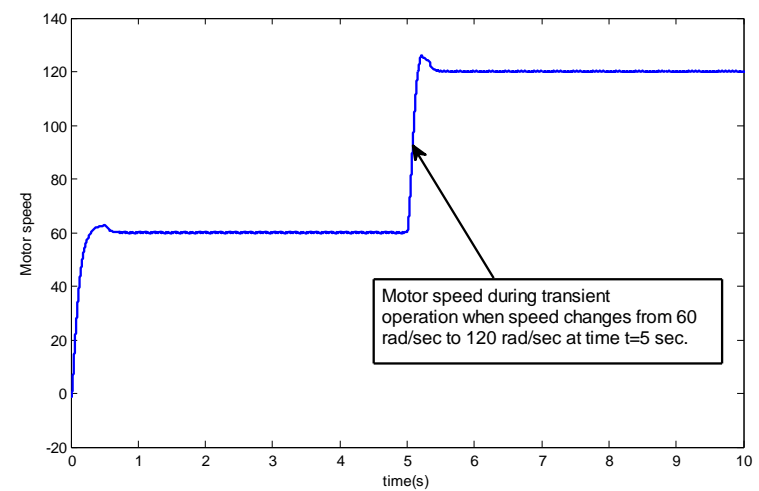

Figure 7(a). Speed.

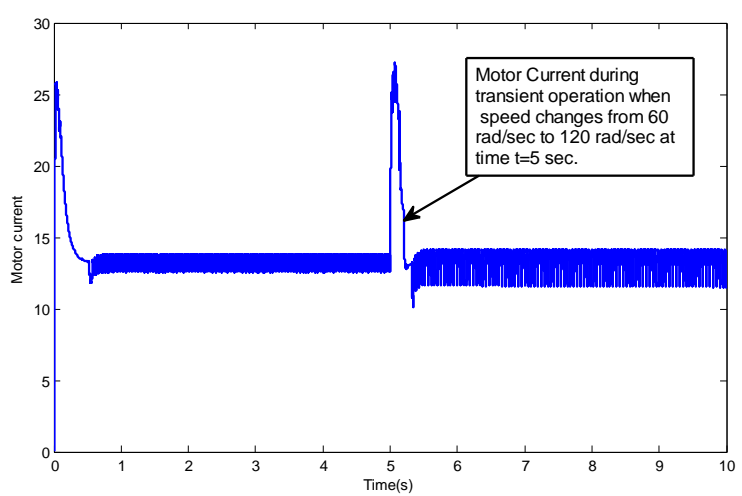

Figure 7(c). Motor current

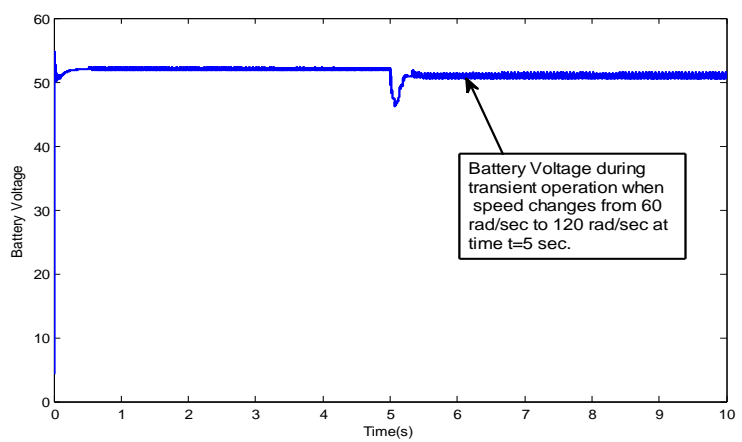

Figure 7(e). Battery voltage.

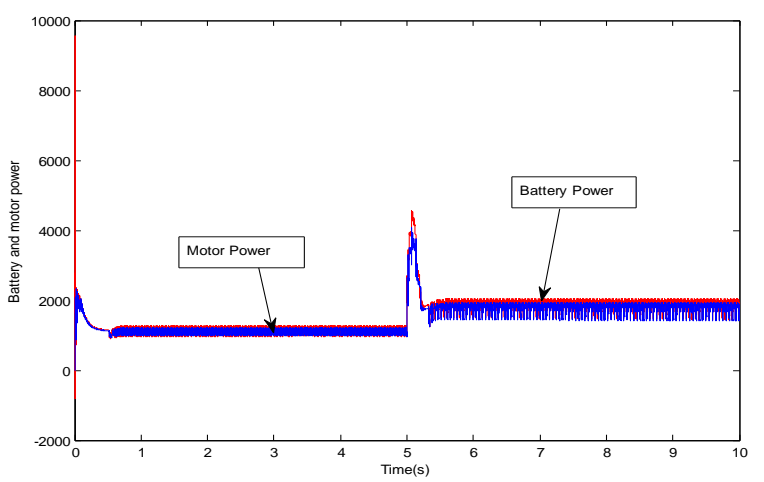

Figure 7(g). Motor and battery power.

Figure 7. Simulation result under motoring mode, speed reference 60 to $120 \mathrm{rad} / \mathrm{sec}$ with time step of $5 \mathrm{sec}$

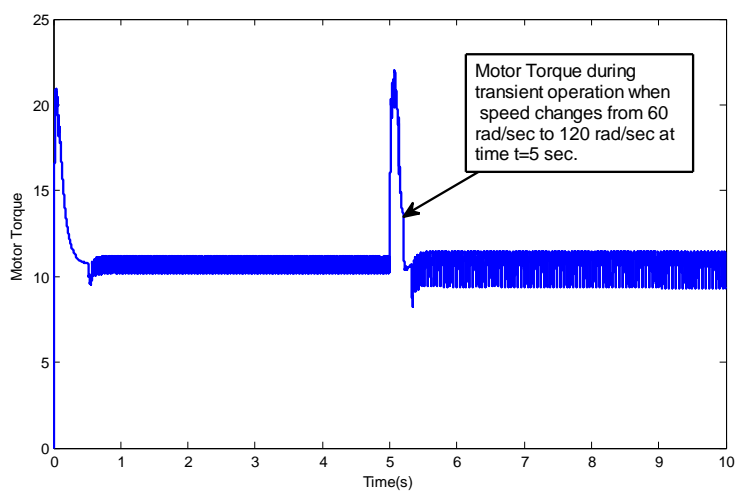

Figure 7(b). Torque

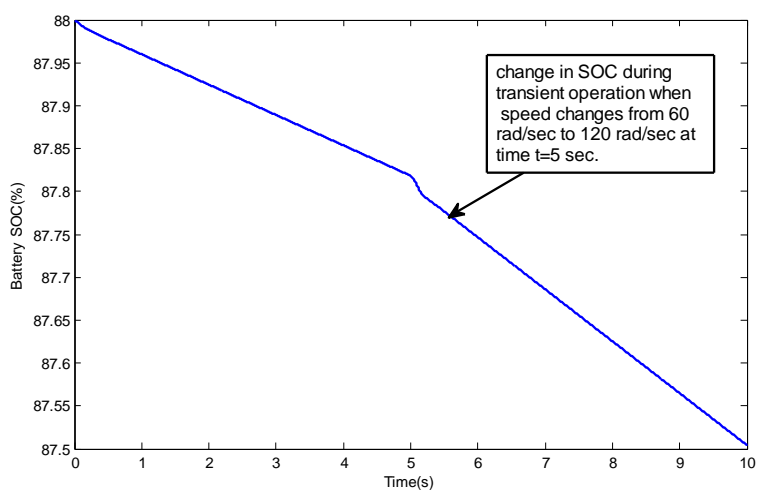

Figure 7(d). Battery SOC.

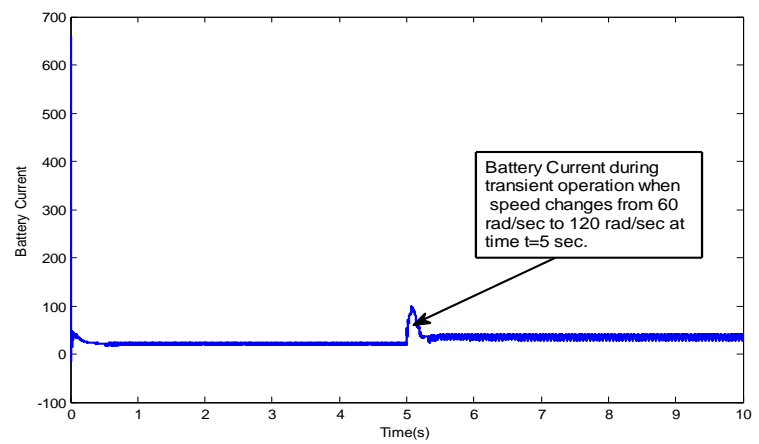

Figure 7(f). Battery current.

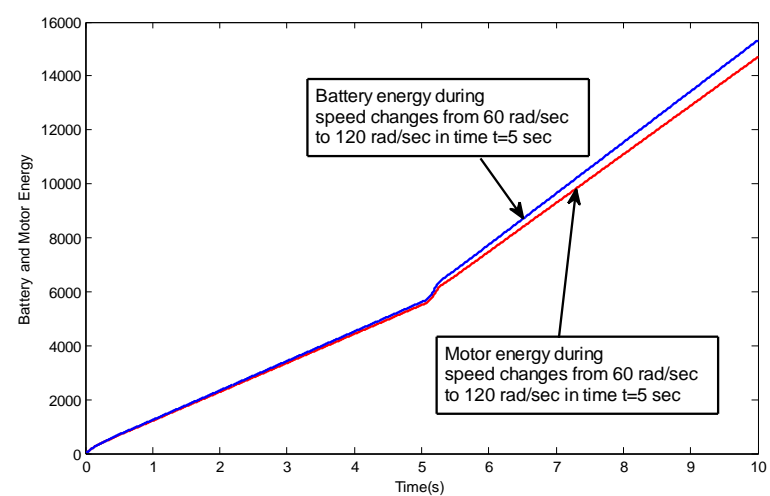

Figure 7(h). Battery and Motor energy. 


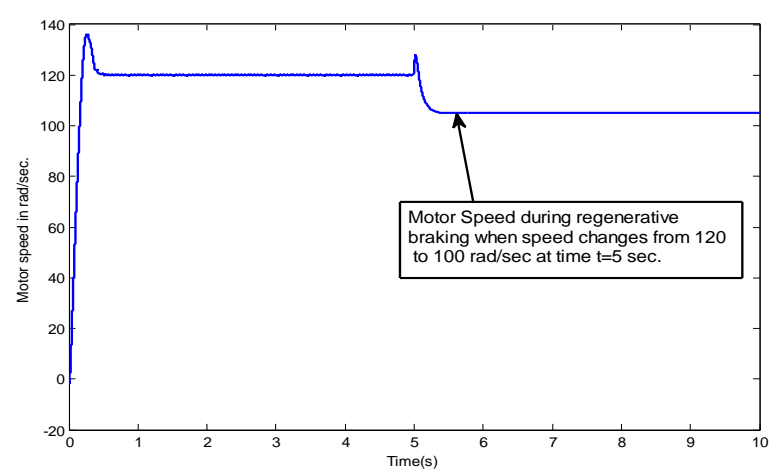

Figure 8(a). Motor speed.

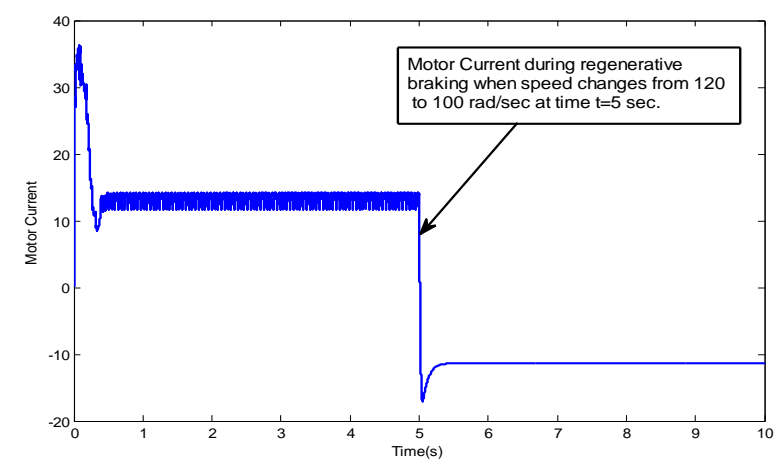

Figure 8(c). Motor current

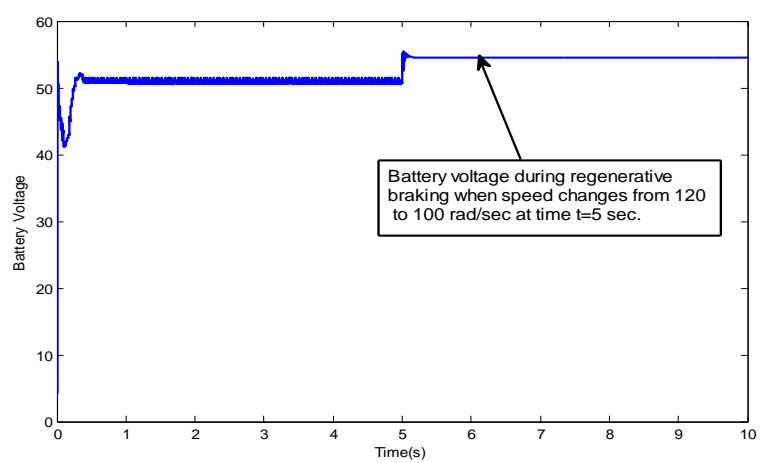

Figure 8(e). Battery voltage.

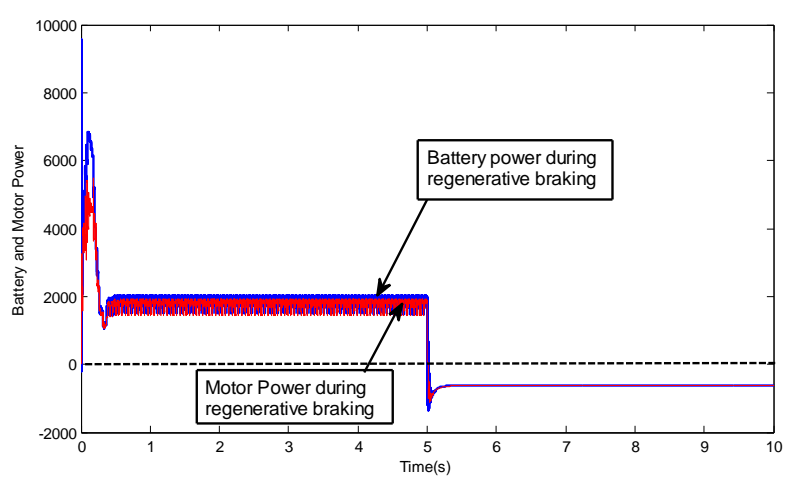

Figure 8(g). Motor and Battery power

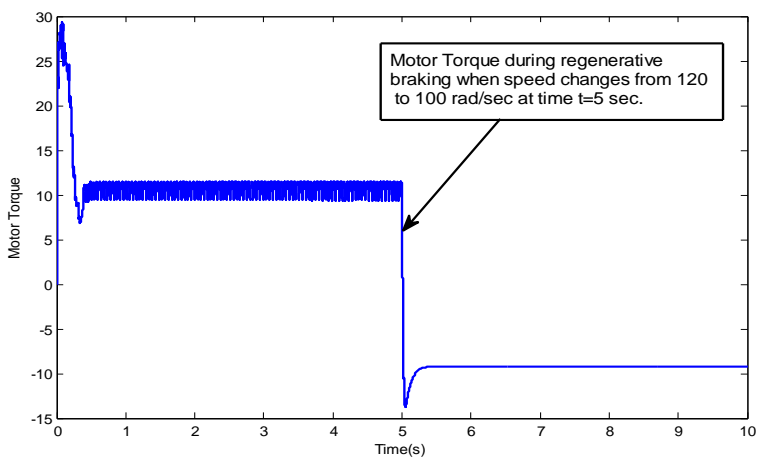

Figure 8(b). Motor torque.

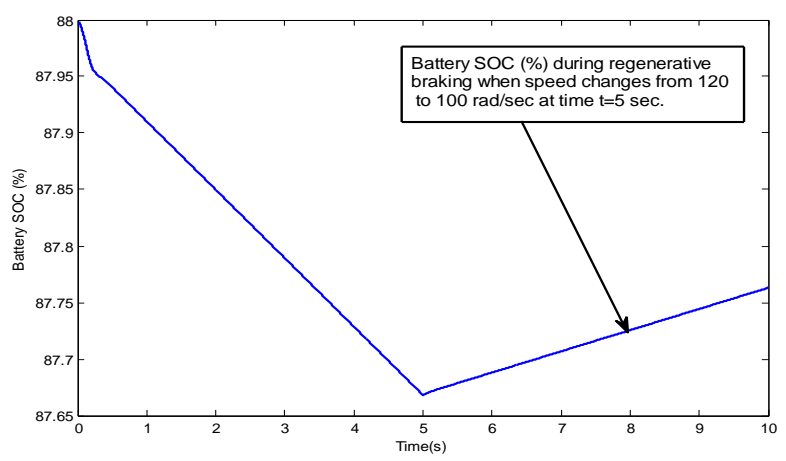

Figure 8(d). Battery State of charge.

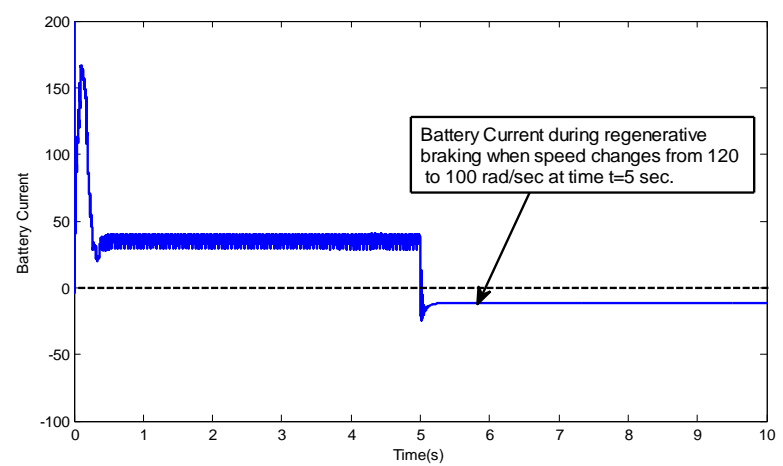

Figure 8(f). Battery current.

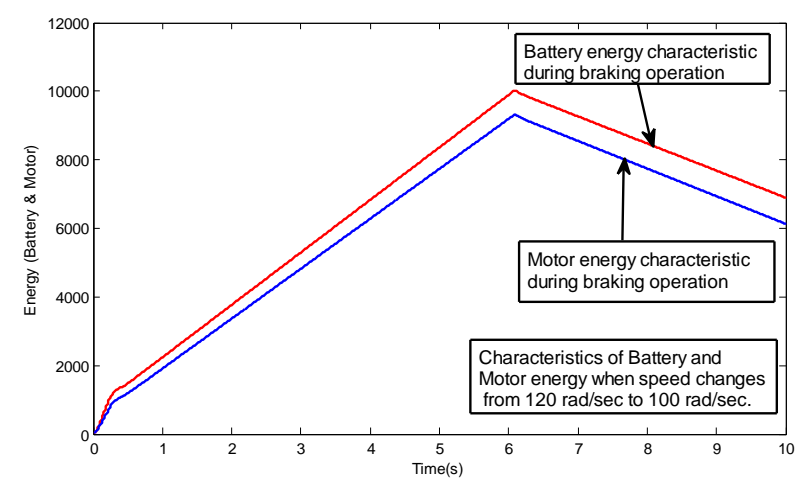

Figure 8(h). Battery and motor energy

Figure 8. Simulation result under regenerative braking mode, speed reference 120 to $0 \mathrm{rad} / \mathrm{sec}$ with time step of $5 \mathrm{sec}$ when torque changes from $10 \mathrm{Nm}$ to $-10 \mathrm{Nm}$. 
Table1. Observations

\begin{tabular}{|c|c|c|}
\hline $\begin{array}{l}\text { Figure } \\
\text { no. }\end{array}$ & Observations & Remarks \\
\hline Figure 6 & Steady state operation, Battery power $=2000 \mathrm{w}$, Motor power $=1920 \mathrm{w}$ & $\begin{array}{l}\text { Battery SOC reduced from } 88 \% \text { to } \\
87.3 \% \text {. }\end{array}$ \\
\hline Figure 7 & $\begin{array}{l}\text { Transient operation, Speed changes from } 60 \mathrm{rad} / \mathrm{sec} \text { to } 120 \mathrm{rad} / \mathrm{sec} \text {. } \\
\text { Battery power changes from } 1600 \text { to } 2000 \mathrm{w} \text {, Motor power changes from } \\
1520 \text { to } 1920 \mathrm{w} \text {. }\end{array}$ & $\begin{array}{l}\text { Battery SOC reduced from } 88 \% \text { to } \\
87.5 \% \text {. }\end{array}$ \\
\hline Figure 8 & $\begin{array}{l}\text { Transient operation (regenerative braking mode) } \\
\text { Ia is positive }(0<t<5 \mathrm{sec}) \text {, Ia is negative }(5 \mathrm{sec}<\mathrm{t}<10 \mathrm{sec})\end{array}$ & $\begin{array}{l}\text { Energy recovered due to due to braking } \\
\text { operation }=3000 \mathrm{~J}\end{array}$ \\
\hline
\end{tabular}

\section{Conclusions}

In this work we demonstrate the performance of a battery operated electric vehicle system and it shows satisfactory performance at different driving condition. The proposed control technique with PI controller find suitable for this electric drive. The performance of the BFEV is verified under forward motoring mode, regenerative mode and when there is step change is speed command. The overall cost and volume of the battery operated electric vehicle is less with the least number of components used in the system.

\section{References}

Jain P.K., Kang W., Soin H., Xi Y., 2002 Analysis and design consideration of a load and line independent Zero voltage switching Full bridge DC/DC Converter topology, IEEE Transaction on Power Electronics, Vol.17, No.5, September. pp 649-657.

Yu W., Lai J.-S., 2008. Ultra High Efficiency Bidirectional DC-DC Converter With multi frequency pulse width modulation APEC 2008,pp 1079-1084.

Zhang J., Lai J.-S., Kim R.-Y., Wensong Yu, 2007. High power density design of a soft-switching high-power bidirectional dc-dc converter, IEEE Transactions on power electronics, Vol.22, No.4, pp 1145-1153, July.

Zhang Y., Sen P.C., 2003. A new soft switching technique for buck, boost, and buck-boost converters, IEEE transactions on Industry Applications, Vol. 39. No.6, November/December, pp. 1775-1782.

Zhang J., Lai J.-S., Yu W., 2008. bidirectional dc-dc converter modeling and unified controller with digital implementation, Applied Power Electronics Conference and Exposition, APEC 2008, pp.1747-1753, Feb.

\section{Biographical notes}

Premananda Pany is currently pursuing PhD degree in Electrical Engineering at MNNIT, Allahabad, India. His research interests are Power Electronics, dc-dc converters, electric drives.

R K Singh, member IEEE and fellow Institution of Engineers (India), is working as a professor, department of Electrical engineering, MNNIT, Allahabad. His area of interest is dc-dc converters, electrical vehicle and distributed generation application. He is reviewer of national and international journal/conferences and working on research projects of government of India. Presently he is chairing IEEE local centre at MN NIT, Allahabad. He is also a student counselor of IET local chapter of MNNIT.

Ramesh K. Tripathi (S'01, M'02) was born in Allahabad on August 01, 1969. He received the B.E. (Hons.) degree in electrical engineering from Regional Engineering College, Durgapur, University of Burdwan, India, in 1989 and the M. Tech. Degree in microelectronics from Institu te of Technology, Banaras Hindu University, Varanasi, India, in 1991. He received Ph.D. degree in power electronics from Indian Institute of Technology, Kanpur, India, in 2002.Since January, 1991; he is faculty in the Department of Electrical Engineering, Motilal Nehru National Institute of Technology Allahabad, India. Currently he is working as Professor in the department of Electrical Engg. MNNIT, Allahabad, India. He has published several papers in national and international journals and conferences. His research interests are Power Electronics, Switch Mode Rectifiers, Utility Friendly Converter Topologies, Magnet Power Supplies, Power Quality, Active Power Filters and Virtual Instrumentation .

Received January 2011

Accepted March 2011

Final acceptance in revised form April 2011 